\title{
TWO DIFFERENT RARE EVENTS OCCURRING SIMULTANEOUSLY IN THE HOUSE MOUSE
}

\author{
MAUREEN MACNEIL \\ Deportment of Genetics, University of Cambridge
}

Received I 0.xii.56

IN an inbred line in which Caracul ( $\mathrm{Ca}$, linkage group VI) had been segregating as a backcross for eight generations, there appeared two males which, from their breeding behaviour, were apparently homozygous for this factor. They were members of the same litter, the first produced by their parents. The latter bred seven Caraculs and four normals in three litters, in good agreement with the expected I : I ratio. The anomalous males (I0/130.3700 and Io/I $30.370 \mathrm{od}$ ) were given several unrelated does besides their first mates from the inbred line, and bred consistently by all of them as homozygous Caraculs, producing no normals out of over two hundred progeny. A summary of these and other relevant data is given in the table.

There is no possibility of mistaken identity. The inbred line segregates in six factors ( $C a$, belted, $b t$, misty, $m$, brown, $b$, silver, $s i$, and Fused, $F u$ ), which are not found in this combination elsewhere in this laboratory. The anomalous males' phenotypes and breeding performance were such that they could only have come from this line, and their parents bred as expected for all six factors.

Neither does it seem likely that $\mathrm{Ca}$ was segregating in an unusual fashion in this line or that any other waving factor was present. The eight previous generations produced severally and in the aggregate ratios of Caracul to normal none of which differed significantly from the expected I : I, and three sibs of the anomalous males, mated to normals, also produced good I : I ratios.

An explanation which at first appears plausible is that the " nonCaracul "parent of the males in question was in fact Caracul. If so, the mating producing them would have been an intercross for Caracul, and the production of two homozygous males out of eleven offspring would not have been surprising. Certainly the ratio seven Caraculs to four normals is not significantly different from $3: \mathrm{I}$. However, the "non-Caracul" parent was scrupulously examined and no trace of curly hair was found. Unfortunately it died before any specific tests of its genotype could be made. But the records showed that it had been outcrossed to an unrelated non-wavy female in a test for another factor. Three young had been classified for waviness and appeared normal. Five others had been killed at five days old but had not been specifically classified for wavy. However, if they had had wavy whiskers this would probably have been noticed. Thus this mating probably produced no wavies out of eight progeny, a result 
which, had the "non-Caracul" actually been a Caracul, could only have occurred by chance with a probability of I in 256 .

It must therefore be concluded that an unusual genetic situation has occurred.

TABLE

The segregation of $\mathrm{Ca}$ and bt from two anomalous males and from their parents

\begin{tabular}{|c|c|c|c|c|c|c|c|c|}
\hline & \multicolumn{5}{|c|}{ Segregation of $C a$ and $b t$} & \multicolumn{3}{|c|}{$\begin{array}{l}\text { Total segregation } \\
\text { (including offspring } \\
\text { not classified for } b t \text { ) }\end{array}$} \\
\hline & $\begin{array}{c}\mathrm{Ca} \\
+\end{array}$ & $\begin{array}{c}C a \\
b t\end{array}$ & + & ${ }_{b t}^{+}$ & Total & $\mathrm{Ca}$ & + & Total \\
\hline $\begin{array}{l}\text { Parents of males were } \\
\qquad \frac{\mathrm{Ca}+}{+b t} q \times \frac{+b t}{+b t} \delta^{\lambda} \text { and gave }\end{array}$ & 4 & 2 & $\ldots$ & 3 & 9 & 7 & 4 & II \\
\hline \multirow[t]{2}{*}{ 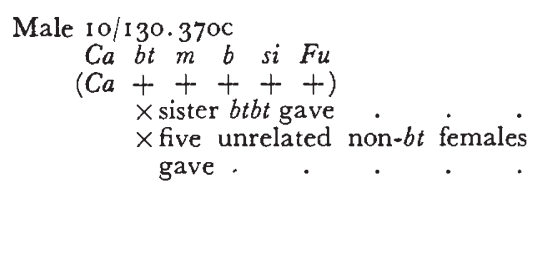 } & $\begin{array}{l}20 \\
\ldots\end{array}$ & $\begin{array}{l}2 \\
\ldots\end{array}$ & $\begin{array}{l}\cdots \\
\ldots\end{array}$ & $\begin{array}{l}\cdots \\
\ldots\end{array}$ & $\begin{array}{l}22 \\
\ldots\end{array}$ & $\begin{array}{r}31 \\
108\end{array}$ & $\begin{array}{l}\cdots \\
\ldots\end{array}$ & $\begin{array}{r}31 \\
108\end{array}$ \\
\hline & 20 & 2 & $\cdots$ & $\ldots$ & 22 & I 39 & $\ldots$ & I 39 \\
\hline \multirow[t]{2}{*}{ 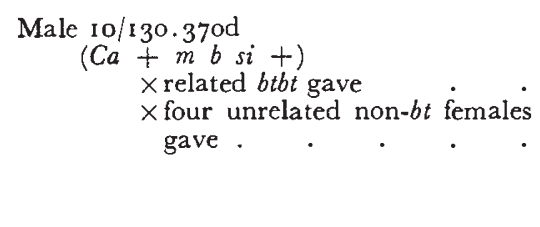 } & $\begin{array}{l}7 \\
\ldots\end{array}$ & $\begin{array}{l}8 \\
\ldots\end{array}$ & $\begin{array}{l}\cdots \\
\cdots\end{array}$ & $\begin{array}{l}\cdots \\
\ldots\end{array}$ & $\begin{array}{l}15 \\
\ldots\end{array}$ & $\begin{array}{l}44 \\
45\end{array}$ & $\begin{array}{l}\cdots \\
\ldots\end{array}$ & $\begin{array}{l}44 \\
45\end{array}$ \\
\hline & 7 & 8 & $\ldots$ & $\ldots$ & 15 & 89 & $\ldots$ & 89 \\
\hline
\end{tabular}

The following explanation appears, at first, to be sufficient :

A mutation may have occurred in the production of chromosome VI in two of the gametes from the non-Ca parent. These mutant gametes may have carried either Caracul, or another dominant curling factor, here given the symbol " $K$ ", closely linked to $C a$.

However, on further inspection of the data, it is apparent that a mutational explanation suffices for only one anomalous male's performance. For as regards the $b t$ locus, the two males bred very differently (see table). 37od produced eight belted offspring by its related $b t b t$ mate, thereby demonstrating that it possessed a $b t$ chromosome from the btbt parent in which the $C a$ or $K$ mutation is supposed to have occurred. But its sib $370 \mathrm{c}$, by a similar mate, produced only two belted offspring out of twenty-two classified for this factor, a very poor fit to the half expected. Moreover, the belt of one of these 
offspring was poorly expressed and the bearer could be construed as a heterozygote. There is no record of the appearance of the belt of the second offspring, but heterozygous penetrance of $b t$ is sufficiently common for one to conjecture that this mouse was a heterozygote also. If, then, it may be said that $370 \mathrm{oc}$ produced no homozygous belteds out of twenty-two, it is not clear what happened to the $b t$ chromosome this mouse should have received from its btbt father. If a mutational explanation is to be used, one must suppose that two mutations occurred simultaneously in this chromosome, one from normal to $C a$ and one from $b t$ to normal.

An explanation for $370 \mathrm{c}$ which requires no mutations at all is as follows.

The $370 \mathrm{c}$ zygote may never have received the $+b t$ chromosome from its father, and the $\mathrm{Ca}+$ one from its mother may have been doubled; or it may have lost the $+b t$ chromosome at some time during the early mitotic divisions. Or, if the two apparently belted offspring which 3700 produced were actually homozygotes, one may say that the $+b t$ chromosome was not lost, but that it contained some defect which either tended to prevent it from reaching the gametes of $370 \mathrm{c}$ or tended to prevent those gametes containing it from reaching the ova of the $b t b t$ mate. The two bt gametes which did fertilise these ova must then have been $C a b t$, that is, crossovers. (This supposition is consistent with the known $C a-b t$ value for males, I I.09 per cent., Mallyon, 195I). This suggests that the defect was carried in the segment between the $C a$ and $b t$ loci. Since the $b t$ received by the sib $370 d$ apparently segregated normally, one may suppose that the $b t b t$ father was at worst heterozygous for the defect. It is conceivable that the same agent was responsible for the mutation to $C a$ or $K$ in one chromosome of the btbt mouse and for the defect in the other.

To sum up, the anomalous facts are as follows. Two $\mathrm{Ca}$ males from a coupling backcross of $C a$ and $b t$ produced nothing but $C a$ offspring. One male, mated in a backcross, segregated $1:$ in normal and belted, while the other, similarly mated, gave only two doubtful belteds out of twenty-two classified. These, and the explanations discussed here, may be graphically represented as follows :

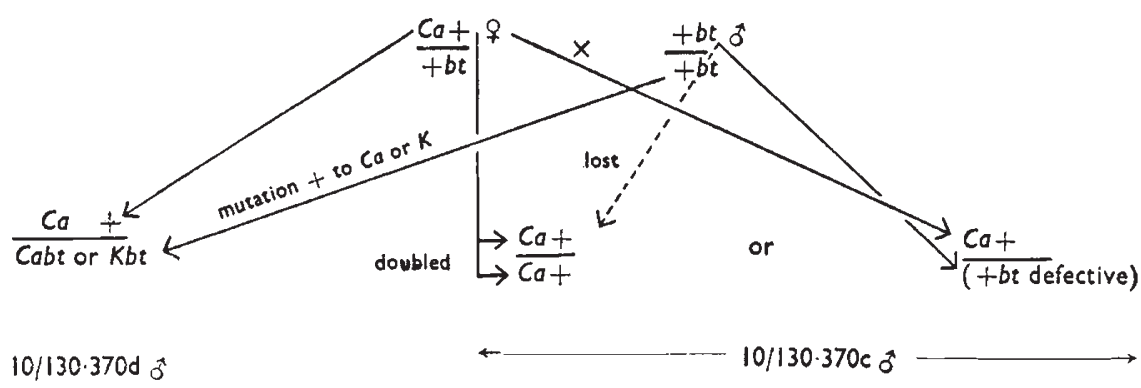


My thanks are due to Professor Sir Ronald Fisher, F.R.s., and to Dr Margaret E. Wallace, for advice.

\section{REFERENCE}

MALLYON, s. A. 195I. A pronounced sex difference in recombination values in the sixth chromosome of the house mouse. Nature, I68, I I 8. 